\title{
Alveolar rhabdomyosarcoma presenting as a lung mass: an uncommon presentation of a less common tumor
}

\author{
Samanjit Kaur Kandola, ${ }^{1}$ Manoj P Rai, ${ }^{1}$ Sowmika L Rao, ${ }^{1}$ Edwin B Marinas ${ }^{2}$
}

\begin{abstract}
${ }^{1}$ Department of Internal Medicine, Michigan State University/Sparrow Hospital, Lansing, Michigan, USA ${ }^{2}$ Department of Pathology, Sparrow Health System, Lansing, Michigan, USA
\end{abstract}

\section{Correspondence to \\ Dr Manoj P Rai,}

manoj.rai@hc.msu.edu

SKK, MPR and SLR contributed equally.

Accepted 16 March 2018

\section{DESCRIPTION}

Case: a male in his early 20 s presented to the emergency department with back pain and abdominal pain for 1 month. The patient also complained of progressively worsening cough and shortness of breath. CT of the chest showed a very large enhancing destructive right lung mass with massive right pleural effusion, which caused a shift of mediastinal structures to the left as well as the significant mass effect on organs in the upper abdomen (figures 1 and 2). CT-guided biopsy of the mass and thoracocentesis was then performed. Histopathology showed nests of small round cells with hyperchromatic nuclei and surrounded by fibrous trabeculae. The tissue had areas of loss of cellular cohesion forming spaces suggestive of an alveolar pattern (figures 3 and 4). It containedPeriodic AcidSchiff (PAS)positive glycogen as well. According to the TNM Classification of malignant tumours (TNM), it was categorised as stage III, T2b N0 M0. Immunohistochemical studies showed positive nuclear staining for myogenin and MyoD1 (figure 5). Thecytoplasmstainied strongly for desmin (figure 6), CD56 and vimentin. Ki67 proliferation fraction was $10 \%$. A diagnosis of alveolar rhabdomyosarcoma (ARMS) was made based on the above findings; a second opinion was obtained from another tertiary hospital for confirmation. $\mathrm{He}$ was then started on vincristine, dactinomycin and cyclophosphamide chemotherapy regimen.

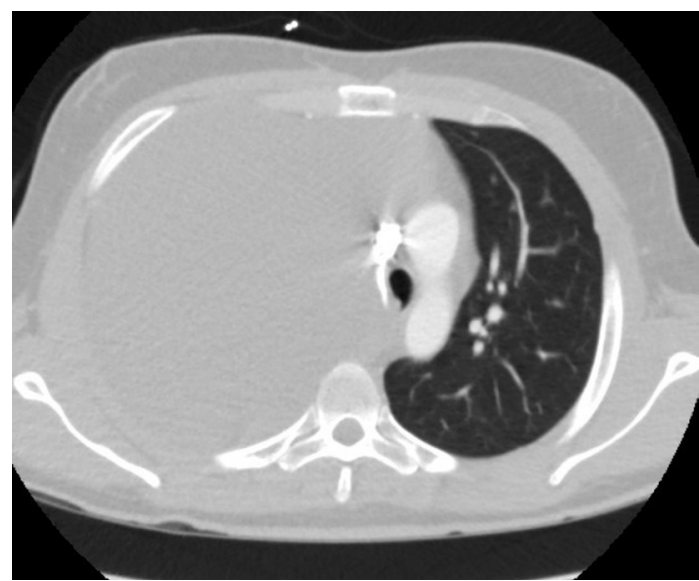

Figure $1 \mathrm{CT}$ of the chest (axial section) showed a very large enhancing destructive right chest wall mass with massive right pleural effusion and shift of mediastinal structures to the left as well as the significant mass effect on organs in the upper abdomen.

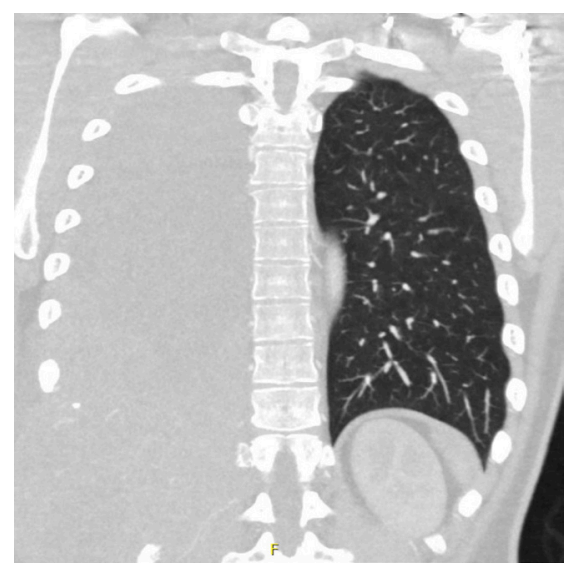

Figure 2 CT of the chest (coronal section) showed a very large enhancing destructive right chest wall mass with massive right pleural effusion and shift of mediastinal structures to the left as well as the significant mass effect on organs in the upper abdomen.

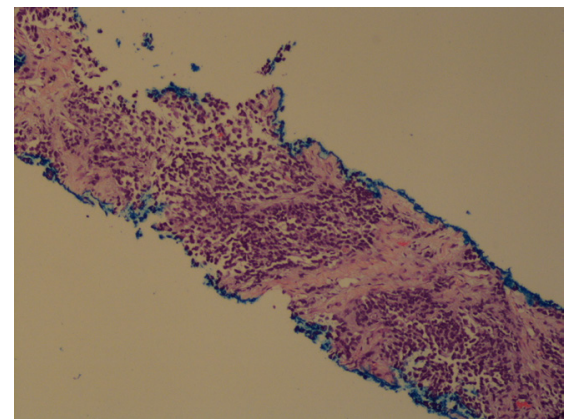

Figure 3 H\&E staining $10 x$.

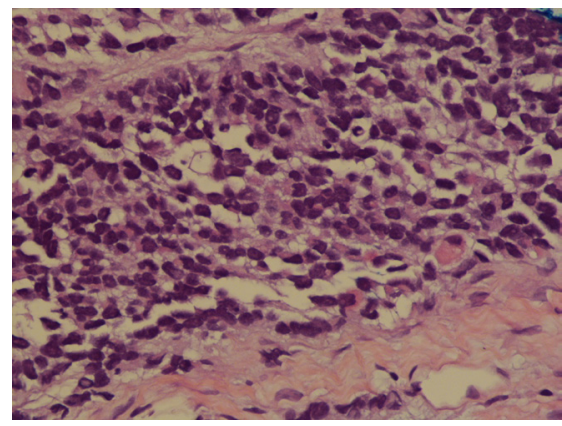

Figure 4 H\&E staining $40 \times$ showing nests of small round cells with hyperchromatic nuclei and surrounded by fibrous trabeculae. 


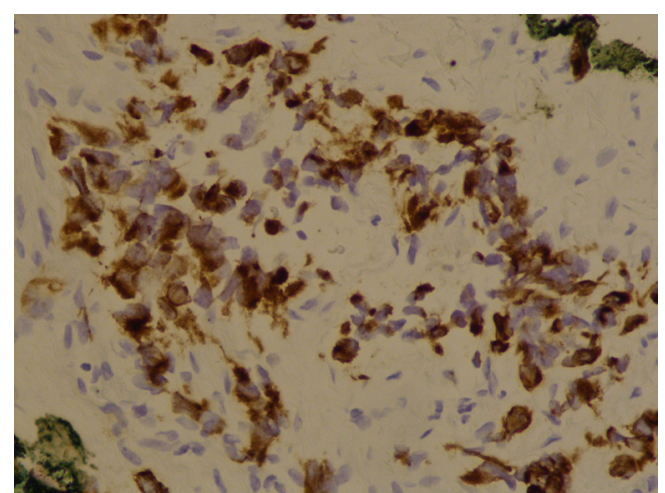

Figure 5 Immunohistochemical stain positive for desmin.

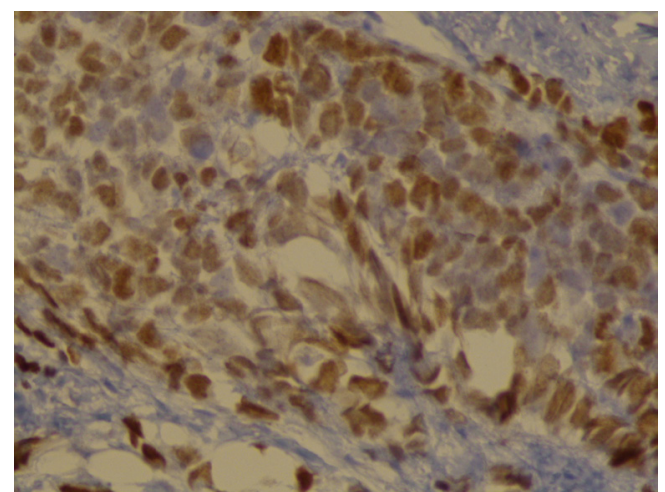

Figure 6 Immunohistochemical stain positive for MyoD1.

The case was discussed with thoracic surgeons from two other tertiary centres who decided to defer surgery since the interval MRI abdomen showed a reduction in the tumour size (figure 7). Thus, a decision was made to start radiation therapy (XRT) and continue chemotherapy. After fourth cycle of chemotherapy, a positron emission tomography-CT was obtained, which showed fluorodeoxyglucose avid pleural-based soft tissue, and pleural thickening of the right lung apex is consistent with progression of the disease (figure 8). Unfortunately, the patient developed acute respiratory failure due to enlargement of the lung mass that required mechanical ventilation; subsequently, the family

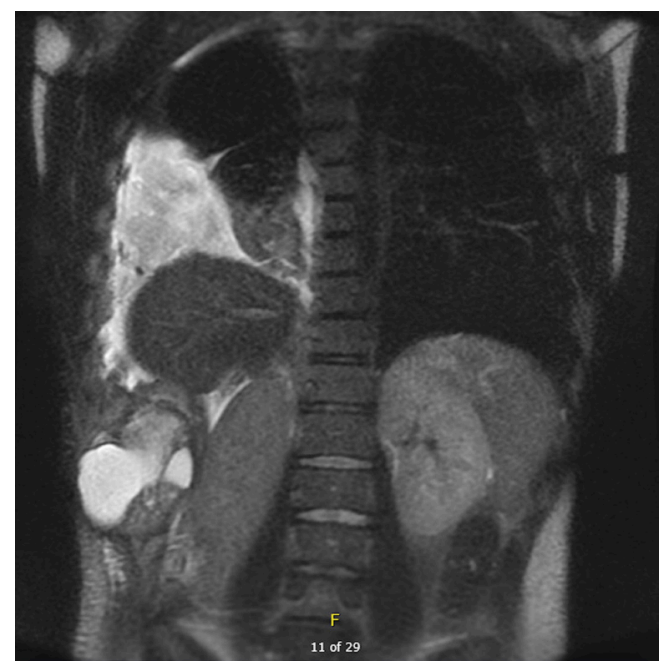

Figure 7 MRI abdomen showing a decrease in the enhancing soft tissue bulk of the tumour.

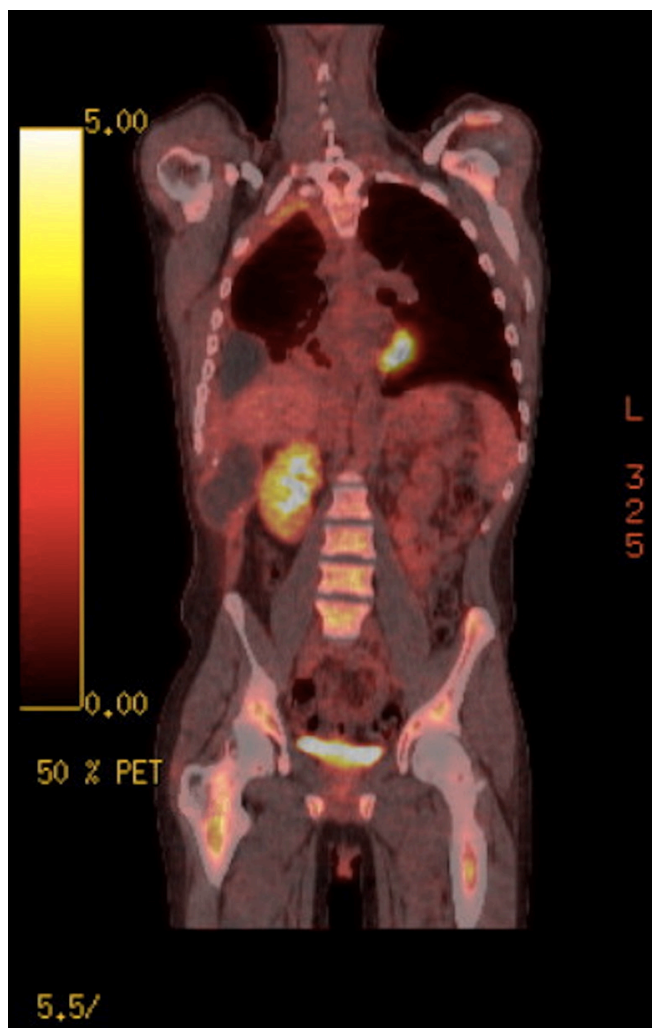

Figure 8 Positron emission tomography (PET)-CT showing fluorodeoxyglucose avid pleural-based soft tissue, and pleural thickening of the right lung apex is consistent with progression of the disease.

decided to terminally wean the patient from ventilator, after which the patient passed away.

ARMS is one of the subtypes of rhabdomyosarcoma (RMS) which is derived from mesenchymal cells. The tumour morphology is similar to alveolar structures of the lungs, so it is named as alveolar rhabdomyosarcoma. The most common sites of occurrence are trunk and extremities. However, it can also occur in other sites such as genitourinary tract, retroperitoneum and, to a lesser extent, in the extremities. ${ }^{1}$ It is a highly malignant skeletal muscle tumour. Majority of the cases are sporadic with no genetic predisposition. The alveolar subtype (ARMS) constitutes approximately another 20\% of RMS cases. ${ }^{2}$ ARMSs differ from embryonal RMS by its occurrence in older patients, distinctive pseudo alveolar pattern, the general absence of strap cells and strong myogenin rather than MyoD1 expression. ${ }^{3}$ Multimodality treatment protocols, including surgery, radiotherapy and combination chemotherapy with vincristine, adriamycin and cyclophosphamide, have improved the

Learning points

- Alveolar rhabdomyosarcoma accounts for $20 \%$ of rhabdomyosarcoma; its most common sites of occurrence are trunk and extremities.

- The symptoms at presentation is due to compression of structures; in our case, the patient developed progressively worsening cough and shortness of breath due to compressive effects of the lung mass.

- Even though new treatment protocols have been developed, prognosis remains poor. 
outcome in the past decades. However, prognosis remains poor with a 5 -year survival of $65 \% .{ }^{4}$ In our case, surgical resection was not performed since there was a reduction in tumour size on the interval scan; he was given four cycles of chemotherapy and a cycle of XRT.

Contributors EBM provided description for the pathology slides.

Funding The authors have not declared a specific grant for this research from any funding agency in the public, commercial or not-for-profit sectors.

Competing interests None declared.

Patient consent Detail has been removed from this case description/these case descriptions to ensure anonymity. The editors and reviewers have seen the detailed information available and are satisfied that the information backs up the case the authors are making.
Provenance and peer review Not commissioned; externally peer reviewed.

(C) BMJ Publishing Group Ltd (unless otherwise stated in the text of the article) 2018. All rights reserved. No commercial use is permitted unless otherwise expressly granted.

\section{REFERENCES}

1. Sarkar D, Ray S, Saha M, et al. Alveolar rhabdomyosarcoma with multiple distal metastases. A case report and review of literature. BMJ Case Rep 2012;2012:bcr2012006523.

2 Punyko JA, Mertens AC, Gurney JG, et al. Long-term medical effects of childhood and adolescent rhabdomyosarcoma: a report from the childhood cancer survivor study. Pediatr Blood Cancer 2005;44:643-53.

3 Gnepp DR. Diagnostic surgical pathology of the head and neck e-book: Elsevier Health Sciences, 2009:1224.

4 Meza JL, Anderson J, Pappo AS, et al. Analysis of prognostic factors in patients with nonmetastatic rhabdomyosarcoma treated on intergroup rhabdomyosarcoma studies II and IV: the Children's Oncology Group. J Clin Oncol 2006;24:3844-51.

Copyright 2018 BMJ Publishing Group. All rights reserved. For permission to reuse any of this content visit

http://group.bmj.com/group/rights-licensing/permissions.

BMJ Case Report Fellows may re-use this article for personal use and teaching without any further permission.

Become a Fellow of BMJ Case Reports today and you can:

- Submit as many cases as you like

- Enjoy fast sympathetic peer review and rapid publication of accepted articles

- Access all the published articles

Re-use any of the published material for personal use and teaching without further permission

For information on Institutional Fellowships contact consortiasales@bmjgroup.com

Visit casereports.bmj.com for more articles like this and to become a Fellow 